Article

\title{
Spermatozoa Survival in Egg Yolk-Based and Soybean-Based Extenders at Ambient and Chilling Temperature in Domestic Turkeys (Meleagris gallopavo)
}

\author{
Isa Mohammed Alkali 1,2,*D, Suleiman Omeiza Asuku ${ }^{1}$, Martina Colombo 2 ${ }^{\mathbb{D}}$, Muhammad Modu Bukar ${ }^{1}$, \\ Mohammed Ahmed Waziri ${ }^{1}$ and Gaia Cecilia Luvoni ${ }^{2}$ D
}

Citation: Alkali, I.M.; Asuku, S.O.; Colombo, M.; Bukar, M.M.; Waziri,

M.A.; Luvoni, G.C. Spermatozoa

Survival in Egg Yolk-Based and Soybean-Based Extenders at Ambient and Chilling Temperature in Domestic Turkeys (Meleagris gallopavo). Animals 2022, 12, 648 . https://doi.org/10.3390/ ani12050648

Academic Editors: Anna Dziekońska and Agnieszka Partyka

Received: 16 December 2021

Accepted: 1 March 2022

Published: 3 March 2022

Publisher's Note: MDPI stays neutral with regard to jurisdictional claims in published maps and institutional affiliations.

Copyright: (C) 2022 by the authors. Licensee MDPI, Basel, Switzerland. This article is an open access article distributed under the terms and conditions of the Creative Commons Attribution (CC BY) license (https:// creativecommons.org/licenses/by/ $4.0 /)$.
1 Department of Theriogenology, Faculty of Veterinary Medicine, University of Maiduguri, Maiduguri 600230, Nigeria; suleimanomeiza06@gmail.com (S.O.A.); mmbukar@unimaid.edu.ng (M.M.B.); mohwaz@unimaid.edu.ng (M.A.W.)

2 Dipartimento di Medicina Veterinaria e Scienze Animali, Università degli Studi di Milano, 26900 Lodi, Italy; martina.colombo@unimi.it (M.C.); cecilia.luvoni@unimi.it (G.C.L.)

* Correspondence: isa.mohammed@unimi.it; Tel.: +39-3515094880 or +234-8061537632

Simple Summary: Hunting pressure and loss of habitat exacerbated by climate change have led to a decline in the number of many galliform species, especially those found in the wild. One such species is the Congo peacock, which has been classified as vulnerable. A domestic galliform species such as the domestic turkey can conceivably be used as a model to research and understand reproduction patterns of related wild and endangered species. The collection, preservation and use of the male gametes for assisted reproductive techniques are key to the successful breeding of such species. This study was aimed at developing a suitable semen extender using two extender formulations (egg yolk-based and soybean-based with or without L-ascorbic acid supplementation) and two storage protocols (ambient temperature and chilled). The results show that both extender formulations preserved turkey semen viability for up to $6 \mathrm{~h}$ at ambient temperature and up to $24 \mathrm{~h}$ at the chilling temperature. In conclusion, the two extenders were similar with regard to semen quality parameters, and L-ascorbic acid supplementation of the turkey semen extenders improved semen quality during liquid storage.

Abstract: Populations of many galliform species have declined mainly due to habitat loss and over-hunting, notably the Congo peacock, which has been classified as a vulnerable species by the International Union for Conservation of Nature (IUCN). The domestic turkey, being a species of least concern, which has been reported to be closely related to peacocks, could serve as a model for the optimization of assisted reproductive technologies for the Congo peacock. This study was aimed at developing a suitable turkey semen extender for artificial insemination in field conditions. Semen was collected using the dorso-abdominal massage technique from seven turkey toms and analyzed. Ejaculates with $>70 \%$ motility and $>80 \%$ live spermatozoa were pooled and divided into four aliquots (four treatments). Each of the four treatments was extended in a soybean-based extender or an egg yolk-based extender, with or without L-ascorbic acid. Two liquid preservation protocols (ambient temperature $\left(35^{\circ} \mathrm{C}\right)$ and chilled $\left.\left(4^{\circ} \mathrm{C}\right)\right)$ were employed, and quality parameters including motility, viability and morphology were evaluated. The results show that the two extenders were similar with regard to semen quality parameters, and L-ascorbic acid supplementation of the turkey semen extenders improved semen quality during liquid storage.

Keywords: domestic turkey; peacock; spermatozoa; soybean; egg yolk; extender; L-ascorbic acid; ambient temperature; chilling temperature 


\section{Introduction}

Populations of many galliform species have declined mainly due to habitat loss and over-hunting [1], including those in captivity [2]. Notably, the Congo peacock (Afropavo congensis), which inhabits the forested areas of the Democratic Republic of the Congo, has been classified as a vulnerable species by the International Union for Conservation of Nature (IUCN) [3]. This was further compounded by climate change and growing armed conflicts in sub-Saharan Africa which could push more species to the IUCN red list [4]. However, there is a general paucity of information in the literature on galliform research, and very few studies are focused on their conservation [1]. Saini et al. [5] reported that both sequence and phylogenic analysis confirmed that peacocks are more related to turkeys than they are to chickens. Therefore, it is conceivable to use domesticated galliforms such as the domestic turkey (Meleagris gallopavo), being a species of least concern, for research and optimization of assisted reproductive technologies (ARTs), which may serve as a model for vulnerable species such as the Congo peacock and perhaps other wild galliforms.

Good-quality semen is the prerequisite to a successful artificial insemination, which is the global best practice for turkey breeding [6]. Turkey semen is highly concentrated and rapidly deteriorates in vitro $[7,8]$. This could be associated with the unique nature of turkey seminal plasma which is composed of both proteins and proteinases [9]. It has been reported that this negative attribute of turkey semen, when compared with other galliforms, may be due to the deleterious effects of some seminal plasma proteins which, in some instances, have been related to a condition of low semen quality called yellow semen syndrome $[10,11]$. In addition, preserving and extending turkey semen beyond six hours without a significant loss of quality has not yet been achieved, especially at higher ambient temperatures [12-15]. Thus, developing an extender that would dilute and maintain the fertilizing capacity of turkey semen at ambient temperature for $24 \mathrm{~h}$ and beyond will permit ARTs in field conditions [16].

The existing poultry semen extenders are mostly minor modifications of the protocols developed in the last four decades $[13,14,17]$. The common constituents considered in these poultry diluents are buffered salt to maintain $\mathrm{pH}$ and osmolarity as well as sources of energy for sperm metabolism [7]. Turkey semen thrives better in an acidic medium with a $\mathrm{pH}$ between 6.5 and 6.8 [17] and osmolarity between 250 and 330 Osm [18,19]. Constant aeration is essential for maintaining the viability of turkey semen during liquid preservation [20,21]. However, even when these conditions are met, commercially acceptable fertility rates are obtained only for a few hours of preservation [12].

Storing extended semen at reduced temperature helps to extend spermatozoan viability by slowing metabolism and inhibiting bacterial growth, thence lowering the accumulation of metabolic byproducts [22-24]. The beneficial positive effect of chicken egg yolk as a non-permeable cryoprotectant in both chilling and sub-zero temperatures has been reported $[25,26]$. It has been conventionally used in commercial semen extenders to provide sperm membrane protection [27]. However, it has been reported that egg yolk supplementation of avian semen has a negative effect on fertility [28], while according to some authors, a lower concentration of egg yolk did not significantly affect both motility and fertility [29]. Recent findings revealed the positive role of low-density lipoproteins (LDL) found in egg yolk on spermatozoan membrane protection. These LDL rapidly bind and thus neutralize seminal plasma proteins which have been incriminated in causing the rapid loss of turkey semen quality [30,31]. In addition, the use of egg yolk in freezing extenders of Indian red jungle fowl improved semen quality and fertility [32]. Similarly, egg yolk plasma which is obtained after eliminating the larger macromolecules and mainly consists of LDL has been reported to improve rooster sperm quality, fertility and hatchability [31].

Similarly, soybean contains a large proportion of LDL called soybean lecithin, similar to egg yolk lecithin, and fatty acids such as stearic, oleic and palmitic acid which have membrane protection potential during cryopreservation and liquid storage of semen [33-35]. Being plant based, soybean has been preferred to replace the conventional egg yolk due to the obvious risk of transmitting pathogenic microorganisms or hormonal substances that 
may negatively affect semen quality when using animal-based products [33,36]. Similarly, international restrictions on potential sources of exotic infectious diseases could limit the transportation of semen extended using egg yolk [35,37].

Generally, poultry semen contains a variety of natural antioxidants including vitamin $\mathrm{E}$, vitamin $\mathrm{C}$ and glutathione, which prevent reactive oxygen species (ROS) from damaging the spermatozoan membrane [38]. However, semen dilution could reduce this ability [39]. Bréque et al. [38] reported that, in avian species, vitamin C may be the prime mover in the complex antioxidant system of sperm storage tubules of the oviduct; thus, we hypothesized that in vitro supplementation of turkey semen with L-ascorbic acid may improve its storage quality.

In order to promote ARTs in field conditions of the tropics, it is pertinent to develop an extender composition that will be suitable for preserving semen at ambient temperature, especially in resource-deficient countries such as those found in sub-Saharan Africa. This study was therefore designed to evaluate the effect of soybean- and egg yolk-based extenders on the liquid storage quality of turkey semen, and to determine the effect of L-ascorbic acid supplementation on turkey semen maintained at ambient and chilling temperatures.

\section{Materials and Methods}

\subsection{Animals}

This study was conducted at the Artificial Insemination Laboratory, Department of Theriogenology, University of Maiduguri, Nigeria. Seven apparently healthy (with no observable signs of disease or ill health) turkey toms and two turkey hens weighing between 8 and $15 \mathrm{~kg}$ were procured from a local poultry market in Maiduguri (Nigeria) for the study. The toms (7-10 months) were managed intensively (in an enclosed hall space with windows, a source of ventilation and light) in individual cage enclosures of $3 \mathrm{ft} \times 3 \mathrm{ft} \times 3 \mathrm{ft}$ dimension and exposed to at least $18 \mathrm{~h}$ of light per day throughout the study period. The hens were kept in adjacent cages to stimulate the toms. Animals were fed daily with commercial feed containing $21 \%$ crude protein and drinking water ad libitum. They were treated for both external and internal parasites using oral ivermectin solution (Kepromec ${ }^{\circledR}$, Devender, The Netherlands) and then allowed to acclimatize for two weeks prior to the semen collection procedure. The toms were conditioned and trained to respond to the semen collection procedure using the dorso-abdominal massage technique as described by Burrows and Quinn [40]. Feathers and danders around the vent were trimmed to facilitate collection of clean ejaculates.

The university ethical committee for the use of animals in research classified semen collection as part of routine management procedures, and we duly adhered to the standard management guidelines stipulated.

\subsection{Experimental Design}

Semen was collected from each tom between 7:00 and 9:00 twice weekly as recommended by Noirault et al. [41] and preliminarily analyzed to evaluate baseline semen characteristics and establish a spermiogram of the study subjects. Each ejaculate was analyzed independently. Then, ejaculates were collected for the experiment from each tom and rapidly evaluated for motility and viability. Ejaculates with $>70 \%$ motility and $>80 \%$ live spermatozoa were pooled and used for the experiment. Each pooled semen (with at least four ejaculates) was divided into four aliquots (treatments). Each of the four treatments was extended in an egg yolk-based extender (EYR) or soybean-based extender (SBR), with or without L-ascorbic acid supplementation. Therefore, the four treatments were EYR, SBR, EYR+L-ascorbic acid and SBR+L-ascorbic acid. The control was kept as such, without any dilution. The final sperm concentration in each aliquot was $1 \times 10^{9} \mathrm{~mL}^{-1}$. Then, each of the four treatments was further divided into two. The first batch was kept in partially open $2 \mathrm{~mL}$ Eppendorf tubes at ambient temperature $\left(35^{\circ} \mathrm{C}\right)$ using a water bath (Memmert waterbath WNB, Schwabach, Germany) to stabilize the temperature and assessed for semen quality immediately after extension and hourly for $7 \mathrm{~h}$. The second batch was 
kept in partially open $2 \mathrm{~mL}$ Eppendorf tubes at $4{ }^{\circ} \mathrm{C}$ in a refrigerator (Haier Thermocool Refrigerator HR 147 S 130L, Hong Kong, China) and assessed for semen quality at 6, 12 and $24 \mathrm{~h}$. The whole experiment was repeated ten times.

\subsection{Extender Preparation}

All chemicals and reagents were purchased from Avantor BDH chemicals (Leicestershire, UK), unless otherwise stated.

Modified Ringer's solution (R) was prepared by dissolving sodium chloride $120 \mathrm{mM}$ (Sigma-Aldrich Chemical Company, St. Louis, MO, USA), potassium chloride $5 \mathrm{mM}$, potassium dihydrogen phosphate $10 \mathrm{mM}$, magnesium phosphate heptahydrate $5 \mathrm{mM}$ and tris hydrochloride $1 \mathrm{mM}$ (Sigma-Aldrich Chemical Company, St. Louis, MO, USA) in double distilled water. Glucose $(1 \%)$ and a penicillin $\mathrm{G}$ and streptomycin combination $\left(1 \mathrm{~g} \mathrm{~L}^{-1}\right)$ were added, and the solution was filtered using Whatman sterile syringe filters $(0.2 \mu \mathrm{m}$ pore size). The soybean-based extender (SBR) contained $\mathrm{R}$ and $1 \%$ soybean milk, while the egg yolk-based extender (EYR) contained R and 5\% egg yolk plasma. Each was supplemented with $20 \mu \mathrm{g} \mathrm{mL}{ }^{-1}$ L-ascorbic acid (Sigma-Aldrich Chemical Company, St. Louis, MO, USA). The $\mathrm{pH}$ was adjusted with normal hydrochloric acid to 6.8-7.

\subsection{Soybean Extraction Method}

The soybean was prepared according to the method described by Singh et al. [42] with slight modification. An amount of $2 \mathrm{~g}$ of soybean was washed and soaked in $100 \mathrm{~mL}$ distilled water and then boiled for $30 \mathrm{~min}$. After boiling, the water was discarded, and the whole soybean was washed again and soaked in $0.25 \%$ sodium trioxocarbonate for $30 \mathrm{~min}$. The solution was discarded afterward, and the soybean was blended with $100 \mathrm{~mL}$ of distilled water. Soybean milk was extracted by filtration through a sieve and double centrifuged, and the supernatant was used for the study.

\subsection{Egg Yolk Plasma Preparation}

Egg yolk extraction was performed according to Ali and Wu [43] with modification. Briefly, freshly laid chicken eggs were collected from the University of Maiduguri farm, washed with running tap water and disinfected with $70 \%$ ethanol. Eggs were manually broken, most of the albumen was removed and the egg yolk was placed on filter paper (Whatman No. 1) and rolled until all the albumen was removed. A sterile syringe was used to aspirate the yolk after piercing through the yolk sac. An equal volume of the yolk and normal saline $(120 \mathrm{mM})$ was placed in sterile tubes and centrifuged twice at $2000 \times g$ for $45 \mathrm{~min}$. The supernatant was used for extender preparation. All extraction processes were conducted at room temperature.

\subsection{Semen Collection}

Semen was collected using the abdominal massage technique described by Burrows and Quinn [40]. Briefly, the collector restrained the turkey tom by its thighs with one hand while the other hand held the collecting tube. An assistant placed the turkey tom between his two legs, massaged the soft part of the abdomen with his left hand to protrude the lateral phallic bodies (tumescence) while simultaneously passing the palm of his right hand gently over the vent and pushed the tail back over the tom's back with the heel of the right hand. The assistant maintained pressure on the tail head until the thumb and index finger of the left hand were in position to gently squeeze behind the phallus. The semen was then milked and collected in a graduated glass tube. Collections were carried out between the months of May and August.

\subsection{Semen Evaluation}

2.7.1. Motility

Motility evaluation was performed by placing one drop of the semen on a glass slide, diluting it with an extender/normal saline and covering it with a glass cover slip. The 
sperm motility was estimated subjectively as reported earlier [44] by at least three operators. Motility was expressed as a percentage of motile spermatozoa with moderate to rapid progressive movement [45].

\subsubsection{Concentration}

The sperm concentration was determined as described in the literature [46] using a Neubauer chamber. Semen was diluted (1:200) with $4 \%$ formal saline before charging the Neubauer chamber.

\subsubsection{Viability}

Sperm viability (live/dead ratio) and morphology were determined using eosinnigrosin-stained slides $[47,48]$. Briefly, an eosin-nigrosin stain smear was created by placing a drop of 1:2 solution of eosin-nigrosin on a glass slide followed by a drop of semen and gentle mixing. A smear of the mixture was allowed to air dry and viewed with immersion oil at $(\times 1000)$ magnification. A differential count on a sample of 200 total spermatozoa from different microscopic fields was performed and classified in percentage of the unstained spermatozoa as "Live" and the stained or partially stained spermatozoa as "Dead" (Figure S1).

\subsubsection{Morphology}

Sperm morphology was evaluated from the eosin-nigrosin-stained smears. A total of 200 spermatozoa were counted, classified and expressed as a percentage of abnormal against normal spermatozoa. Various morphological defects were also classified and grouped into four categories, viz., acrosomal (detachment and swelling of the acrosome), head (bent head, swollen head, looped head and detached head), mid-piece (swollen, bent or thickened mid-piece and cytoplasmic droplet) or tail defects (bent tail, looped tail, coiled tail and detached tail), as described by Alkan et al. [49].

\subsection{Statistical Analyses}

Data generated were summarized and expressed as mean \pm SD (standard deviation) and presented in tables. Multivariate analysis of variance (MANOVA) was employed to evaluate the effect of the extender and ascorbic acid supplementation, while repeated measures analysis of variance was performed to test the effect of time across the different storage temperatures. A chi-square test was used to test associations between proportions of different sperm morphological defects. Values of $p<0.05$ were considered statistically significant. The statistical package IBM SPSS version 20 was used for the analysis.

\section{Results}

\subsection{Baseline Spermiogram of Turkey Toms Used for the Study}

The semen characteristics of turkey toms enrolled in the study evaluated before the semen preservation study are presented as the mean \pm SD in the Supplementary Material (Table S1). Eighty-eight percent ( $88.4 \%$ ) of the ejaculates collected were creamy white in color (not presented in the table). A photomicrograph of fresh undiluted turkey semen stained with eosin-nigrosin is presented in the Supplementary Material (Figure S1).

\subsection{Quality of Preserved Turkey Semen}

Generally, there was no significant variation between the two extenders with regard to semen quality ( $p=0.310$ Wilks' lambda test), while ascorbic acid supplementation had a significant effect on quality parameters ( $p=0.001$ Wilks' lambda test). Similarly, time of storage had a significant effect ( $p=0.001$ Wilks' lambda test) on the semen quality across the storage temperatures. 


\subsubsection{Sperm Motility Assessment among Different Semen Extenders}

Sperm motility in the extended semen evaluated hourly for seven hours at ambient temperature is presented in Table 1 . There was no significant difference $(p=0.483)$ between the egg yolk-based and soybean-based semen extenders. Similarly, Table 2 presents the mean percentage sperm motility of extended and chilled semen evaluated at 6,12 and $24 \mathrm{~h}$. There was no significant difference $(p=0.577)$ in motility values between the two extenders. However, motility was significantly $(p=0.003)$ higher in ascorbic acid-supplemented groups.

Table 1. Motility (\%) of turkey spermatozoa during $7 \mathrm{~h}$ of storage at ambient temperature.

\begin{tabular}{|c|c|c|c|c|c|c|c|c|}
\hline \multirow{2}{*}{ Treatment Hroups } & \multicolumn{8}{|c|}{ Time (Hours) } \\
\hline & 0 & 1 & 2 & 3 & 4 & 5 & 6 & 7 \\
\hline Egg yolk based (EYR) & $84.0 \pm 8.4^{\mathrm{a}}$ & $74.0 \pm 8.4^{\mathrm{a}}$ & $69.5 \pm 7.6^{a}$ & $54.0 \pm 13.5^{\mathrm{a}}$ & $43.0 \pm 13.4^{\mathrm{a}}$ & $26.0 \pm 19.6^{a}$ & $16.6 \pm 19.0^{\mathrm{a}}$ & $7.0 \pm 13.4^{a}$ \\
\hline Soybean based (SBR) & $81.2 \pm 5.2^{\mathrm{a}}$ & $73.5 \pm 8.2^{\mathrm{a}}$ & $67.0 \pm 9.8^{\mathrm{a}}$ & $54.0 \pm 10.8^{\mathrm{a}}$ & $43.0 \pm 11.6^{\mathrm{a}}$ & $29.0 \pm 12.9^{a}$ & $17.0 \pm 10.6^{\mathrm{a}}$ & $4.0 \pm 7.0^{\mathrm{a}}$ \\
\hline EYR + L-ascorbic acid & $87.1 \pm 5.1^{\mathrm{b}}$ & $80.0 \pm 9.4^{b}$ & $71.0 \pm 9.9^{\mathrm{a}}$ & $59.0 \pm 4.0^{\mathrm{a}}$ & $47.0 \pm 14.9^{\mathrm{a}}$ & $35.0 \pm 16.5^{a}$ & $22.0 \pm 14.0^{\mathrm{a}}$ & $11.0 \pm 8.8^{a}$ \\
\hline SBR + L-ascorbic acid & $86.8 \pm 7.4^{b}$ & $80.0 \pm 8.2^{b}$ & $68.0 \pm 9.2^{\mathrm{a}}$ & $54.0 \pm 11.7^{\mathrm{a}}$ & $43.0 \pm 15.7^{\mathrm{a}}$ & $31.0 \pm 17.3^{\mathrm{a}}$ & $17.0 \pm 13.4^{\mathrm{a}}$ & $7.0 \pm 9.5^{\mathrm{a}}$ \\
\hline
\end{tabular}

The data provided in the table are percentages (\%) of the mean motility \pm SD of the pooled turkey ejaculates included in the study. Values in the same column with different superscripts differ significantly $(p<0.05)$.

Table 2. Motility (\%) of turkey spermatozoa over $24 \mathrm{~h}$ at $4{ }^{\circ} \mathrm{C}$.

\begin{tabular}{cccc}
\hline \multirow{2}{*}{ Treatment Groups } & \multicolumn{3}{c}{ Time (Hours) } \\
\cline { 2 - 4 } & $\mathbf{6}$ & $\mathbf{1 2}$ & $\mathbf{2 4}$ \\
\hline Egg yolk based (EYR) & $64.0 \pm 9.7^{\mathrm{a}}$ & $45.0 \pm 15.1^{\mathrm{a}}$ & $30.5 \pm 14.6^{\mathrm{a}}$ \\
Soybean based (SBR) & $61.0 \pm 12.9^{\mathrm{a}}$ & $46.0 \pm 17.8^{\mathrm{a}}$ & $29.0 \pm 20.4^{\mathrm{a}}$ \\
EYR + L-ascorbic acid & $77.5 \pm 4.3^{\mathrm{b}}$ & $64.0 \pm 5.2^{\mathrm{b}}$ & $47.0 \pm 7.5^{\mathrm{b}}$ \\
SBR + L-ascorbic acid & $76.5 \pm 4.7^{\mathrm{b}}$ & $63.0 \pm 8.2^{\mathrm{b}}$ & $42.0 \pm 12.3^{\mathrm{b}}$ \\
\hline
\end{tabular}

The data provided in the table are percentages (\%) of the mean motility \pm SD of the pooled turkey ejaculates included in the study. Values in the same column with different superscripts differ significantly $(p<0.05)$.

\subsubsection{Sperm Viability Assessment among Different Semen Extenders}

Sperm viability evaluated hourly for seven hours at ambient temperature is presented in Table 3; there was no significant difference $(p=0.904)$ between the egg yolk-based and soybean-based semen extenders, but there was a significant difference $(p=0.030)$ between ascorbic acid-supplemented and non-supplemented groups. Similarly, in the chilled preserved semen evaluated at 6,12 and $24 \mathrm{~h}$ (Table 4), there was no significant difference $(p=0.844)$ in viability between the two extenders. However, ascorbic acidsupplemented treatments were significantly higher in viability at 6 and $12 \mathrm{~h}$, while at $24 \mathrm{~h}$, all treatments were statistically the same. On the other hand, both motility and viability indices were significantly $(p=0.015)$ higher after $24 \mathrm{~h}$ of chilled preservation than after seven hours at ambient temperature.

Table 3. Viability (\%) of turkey spermatozoa during $7 \mathrm{~h}$ of storage at ambient temperature.

\begin{tabular}{|c|c|c|c|c|c|c|c|c|}
\hline \multirow{2}{*}{ Treatment Groups } & \multicolumn{8}{|c|}{ Time (Hours) } \\
\hline & 0 & 1 & 2 & 3 & 4 & 5 & 6 & 7 \\
\hline Egg yolk based (EYR) & $94.0 \pm 2.6^{\mathrm{a}}$ & $90.6 \pm 2.6^{a}$ & $85.7 \pm 5.3^{a}$ & $83.0 \pm 6.0^{\mathrm{a}}$ & $78.9 \pm 6.3^{a}$ & $74.6 \pm 9.1^{\mathrm{a}}$ & $70.4 \pm 9.1^{\mathrm{a}}$ & $61.8 \pm 16.4^{a}$ \\
\hline Soybean based (SBR) & $92.5 \pm 3.1^{a}$ & $88.8 \pm 5.5^{\mathrm{a}}$ & $87.2 \pm 5.4^{\mathrm{a}}$ & $82.5 \pm 5.9^{a}$ & $80.9 \pm 7.5^{a}$ & $75.7 \pm 9.2^{a}$ & $70.9 \pm 14.0^{a}$ & $63.4 \pm 17.8^{a}$ \\
\hline EYR + L-ascorbic acid & $99.5 \pm 0.9^{b}$ & $99.3 \pm 1.0^{b}$ & $95.4 \pm 3.3^{b}$ & $91.3 \pm 3.2^{b}$ & $90.3 \pm 4.9^{b}$ & $85.2 \pm 6.0^{b}$ & $79.9 \pm 8.6^{b}$ & $74.7 \pm 9.2^{b}$ \\
\hline $\mathrm{SBR}+\mathrm{L}$-ascorbic acid & $99.4 \pm 1.1^{b}$ & $99.2 \pm 0.9^{b}$ & $95.8 \pm 2.7^{b}$ & $93.3 \pm 3.3^{b}$ & $90.3 \pm 3.1^{b}$ & $85.8 \pm 6.2^{b}$ & $80.9 \pm 7.1^{b}$ & $74.2 \pm 5.6^{b}$ \\
\hline
\end{tabular}

The data provided in the table are percentages (\%) of the mean viability \pm SD of the pooled turkey ejaculates included in the study. Values in the same column with different superscripts differ significantly $(p<0.05)$. 
Table 4. Viability (\%) of turkey spermatozoa over $24 \mathrm{~h}$ at $4{ }^{\circ} \mathrm{C}$.

\begin{tabular}{cccc}
\hline \multirow{2}{*}{ Treatment Groups } & \multicolumn{3}{c}{ Time (Hours) } \\
\cline { 2 - 4 } & $\mathbf{6}$ & $\mathbf{1 2}$ & $\mathbf{2 4}$ \\
\hline Egg yolk based (EYR) & $94.5 \pm 2.6^{\mathrm{a}}$ & $90.0 \pm 5.7^{\mathrm{a}}$ & $85.6 \pm 5.8^{\mathrm{b}}$ \\
Soybean based (SBR) & $94.9 \pm 3.2^{\mathrm{a}}$ & $91.4 \pm 4.5^{\mathrm{a}}$ & $89.5 \pm 3.9^{\mathrm{b}}$ \\
EYR + L-ascorbic acid & $97.9 \pm 2.5^{\mathrm{b}}$ & $94.0 \pm 3.9^{\mathrm{b}}$ & $88.5 \pm 5.0^{\mathrm{b}}$ \\
SBR + L-ascorbic acid & $97.9 \pm 2.9^{\mathrm{b}}$ & $94.1 \pm 3.4^{\mathrm{b}}$ & $89.7 \pm 3.7^{\mathrm{b}}$ \\
\hline
\end{tabular}

The data provided in the table are percentages (\%) of the mean viability \pm SD of the pooled turkey ejaculates included in the study. Values in the same column with different superscripts differ significantly $(p<0.05)$.

\subsubsection{Sperm Morphology Assessment}

The average morphological defects of spermatozoa in the extended semen evaluated hourly for seven hours at ambient temperature and the chilled semen evaluated at 6, 12 and $24 \mathrm{~h}$ are presented in Tables 5 and 6, respectively. There was no significant difference $(p=0.094)$ between the egg yolk-based and soybean-based semen extenders. However, the ascorbic acid-supplemented groups presented significantly $(p=0.001)$ lower values.

Table 5. Morphological defects (\%) of turkey spermatozoa during $7 \mathrm{~h}$ of storage at ambient temperature.

\begin{tabular}{|c|c|c|c|c|c|c|c|c|}
\hline \multirow{2}{*}{ Treatment Groups } & \multicolumn{8}{|c|}{ Time (Hours) } \\
\hline & 0 & 1 & 2 & 3 & 4 & 5 & 6 & 7 \\
\hline Egg yolk based (EYR) & $7.7 \pm 3.7^{\mathrm{a}}$ & $10.2 \pm 3.1^{a}$ & $12.2 \pm 4.0^{\mathrm{a}}$ & $17.9 \pm 5.7^{a}$ & $23.6 \pm 7.3^{a}$ & $24.2 \pm 6.0^{a}$ & $26.0 \pm 6.1^{a}$ & $37.2 \pm 9.9^{\circ}$ \\
\hline Soybean based (SBR) & $6.9 \pm 3.1^{\mathrm{a}}$ & $8.0 \pm 2.9^{b}$ & $9.0 \pm 2.7^{b}$ & $15.9 \pm 3.1^{\mathrm{a}}$ & $21.2 \pm 7.2^{\mathrm{a}}$ & $23.5 \pm 6.3^{\mathrm{a}}$ & $27.2 \pm 6.9^{a}$ & $35.8 \pm 8.2^{\circ}$ \\
\hline EYR + L-ascorbic acid & $2.5 \pm 1.2^{b}$ & $4.4 \pm 2.0^{c}$ & $5.8 \pm 2.7^{c}$ & $7.4 \pm 1.9^{b}$ & $9.5 \pm 2.7^{b}$ & $12.2 \pm 3.3^{b}$ & $15.0 \pm 3.6^{b}$ & $17.6 \pm 2.7^{b}$ \\
\hline SBR + L-ascorbic acid & $2.3 \pm 1.2^{b}$ & $2.6 \pm 1.1^{\mathrm{d}}$ & $4.3 \pm 1.5^{\mathrm{d}}$ & $6.2 \pm 2.3^{b}$ & $8.4 \pm 2.0^{b}$ & $10.4 \pm 2.4^{b}$ & $12.7 \pm 3.4^{b}$ & $15.2 \pm 1.9^{\mathrm{b}}$ \\
\hline
\end{tabular}

The data provided in the table are percentages (\%) of the mean morphological defects \pm SD of the pooled turkey ejaculates included in the study. Values in the same column with different superscripts differ significantly $(p<0.05)$.

Table 6. Morphological defects (\%) of turkey spermatozoa over $24 \mathrm{~h}$ at $4{ }^{\circ} \mathrm{C}$.

\begin{tabular}{cccc}
\hline \multirow{2}{*}{ Treatment Groups } & \multicolumn{3}{c}{ Time (Hours) } \\
\cline { 2 - 4 } & $\mathbf{6}$ & $\mathbf{1 2}$ & $\mathbf{2 4}$ \\
\hline Egg yolk based (EYR) & $10.2 \pm 3.7^{\mathrm{a}}$ & $11.3 \pm 2.8^{\mathrm{a}}$ & $16.4 \pm 2.2^{\mathrm{a}}$ \\
Soybean based (SBR) & $7.9 \pm 4.6^{\mathrm{a}}$ & $12.8 \pm 3.5^{\mathrm{a}}$ & $20.1 \pm 5.4^{\mathrm{b}}$ \\
EYR + L-ascorbic acid & $3.9 \pm 1.0^{\mathrm{b}}$ & $7.3 \pm 3.1^{\mathrm{b}}$ & $10.2 \pm 3.3^{\mathrm{c}}$ \\
SBR + L-ascorbic acid & $3.6 \pm 1.2^{\mathrm{b}}$ & $6.3 \pm 2.0^{\mathrm{b}}$ & $9.5 \pm 2.1^{\mathrm{c}}$ \\
\hline
\end{tabular}

The data provided in the table are percentages (\%) of the mean morphological defects \pm SD of the pooled turkey ejaculates included in the study. Values in the same column with different superscripts differ significantly $(p<0.05)$.

Table 7 presents the proportion of different morphological abnormalities in fresh, chilled and ambient temperature-preserved samples. Mid-piece defects were significantly higher $(p=0.001)$ in fresh semen than in the treated semen, while tail defects increased in preserved semen. 
Table 7. Proportions of different sperm morphological defects in different preservation conditions applied to turkey semen.

\begin{tabular}{ccccc}
\hline Preservation & Acrosome & $\begin{array}{c}\text { Percentage (\%) } \\
\text { Head }\end{array}$ & Mid-Piece & Tail \\
\hline $\begin{array}{c}\text { Fresh semen } \\
\mathrm{N}=173\end{array}$ & $0.0^{\mathrm{a}}$ & $11.8^{\mathrm{a}}$ & $44.4^{\mathrm{a}}$ & $43.8^{\mathrm{a}}$ \\
\hline $\begin{array}{c}\text { Ambient } \\
\text { temperature } \\
\mathrm{N}=799\end{array}$ & $1.5^{\mathrm{a}}$ & $15.4^{\mathrm{a}}$ & $19.2^{\mathrm{b}}$ & $63.8^{\mathrm{b}}$ \\
\hline $\begin{array}{c}\text { Chilled }\left(4^{\circ} \mathrm{C}\right) \\
\mathrm{N}=1399\end{array}$ & $3.6^{\mathrm{b}}$ & $17.0^{\mathrm{a}}$ & $20.5^{\mathrm{b}}$ & $58.9^{\mathrm{c}}$ \\
\hline
\end{tabular}

$\mathrm{N}=$ total number of morphological defects. Values in the same column with different superscripts differ significantly $(p<0.05)$.

\section{Discussion}

The current study showed that soybean- and egg yolk-based extenders were able to preserve, both at ambient and chilling temperatures, the quality parameters of turkey semen, while there was a significant reduction in turkey sperm morphological defects through the period of preservation when the extenders were supplemented with L-ascorbic acid. Additionally, to the best of our knowledge, this is the first time a study describing the effect of egg yolk plasma and soybean on the liquid storage of turkey semen has been reported.

A baseline spermiogram from the fresh semen of turkey toms was established in the present study. It was quite similar to other reported semen characteristics of turkey toms found in other parts of Nigeria [50-52]. However, slightly higher values were reported in exotic breeds $[41,45,50,51,53]$.

In this study, higher motility and viability indices were recorded $24 \mathrm{~h}$ after preservation at $4{ }^{\circ} \mathrm{C}$ compared with the values recorded after $7 \mathrm{~h}$ at ambient temperature. This delineated the importance of a low temperature for liquid preservation of turkey semen $[22,54]$. However, there was a decrease in motility during the $7 \mathrm{~h}$ of holding time at ambient temperature and through the $24 \mathrm{~h}$ of chilled storage in all the extender preparations, as reported in crane semen $[12,14,15,55]$. This is conceivable because at ambient temperature, spermatozoan metabolism is at its peak with a resultant buildup of metabolic byproducts which could slow down sperm motility.

In the current study, there was no difference in semen quality parameters between egg yolk-based and soybean-based extenders, which means soybean is similar to egg yolk and can replace it in preservation media of turkey semen. The survival of turkey spermatozoa in these extenders could be attributed to the neutralization effect of LDL on seminal plasma proteins and other macromolecules that are found in turkey semen [30]. Although the use of whole egg yolk as a supplement in poultry extenders has been associated with reduced fertility, it could be associated with the inadvertent inclusion of the inner perivitelline membrane of egg yolk in the yolk homogenate during yolk collection. The inner perivitelline membrane has been associated with in vitro activation of acrosomal activity of avian sperm [56,57]. Thus, in order to mitigate such an occurrence in this study, we isolated the egg yolk plasma fraction which contained mainly LDL.

Success with the use of soybean-based extenders has been achieved in many animal species $[34,35,58-60]$. Significantly higher post-thaw bovine sperm motility in a soybean lecithin-based extender than Tris-egg yolk diluents has been reported [59]. Similarly, Singh et al. [42] observed that a $25 \%$ soy-based extender produced a better sperm quality in chilled bovine semen. On the other hand, no significant difference was observed in post-thaw semen quality when $1 \%$ soy lecithin was compared with $20 \%$ egg yolk supplementation [61]. It should be highlighted that the aforementioned comparable results between egg yolk- and soybean-based extenders were obtained with a low concentration of soymilk ( $1 \%)$. Similarly, in this study, we reported a comparable result between $1 \%$ soybean 
and 5\% egg yolk plasma. This echoes similar findings on roosters and some mammalian species $[31,34,35,59,60]$. Nonetheless, Singh et al. [42] reported that sperm quality was negatively affected when the soybean milk concentration was greater than $30 \%$. Several studies using a wide range of soybean milk concentrations found wide variation in the results, and the varying degrees of success showed the lack of standardization in the use of soybean-based extenders [31,34,35,42,59-61]. This could be associated with the sperm plasmalemma or the seminal plasma composition between species which may determine the required concentration of soybean milk to be used in extenders [33].

The semen viability index in both preservation conditions exhibited a similar pattern to that of motility. However, viability was sustained even when the motility was almost zero. This indicates that motility is the most sensitive parameter to external factors, as also reported with Bestville poultry semen extenders [54]. Sexton [14] also found that storing turkey semen diluted $(1: 2)$ with Lake's solution at $25^{\circ} \mathrm{C}$ or $5{ }^{\circ} \mathrm{C}$ for $30 \mathrm{~min}$ had a profound negative effect on motility, but little effect on the viability index.

In the current report, there was a significant difference between non-supplemented and ascorbic acid-supplemented extenders, with higher values recorded in the latter. This echoes earlier findings where the quality parameters of rooster semen were improved with ascorbic acid supplementation $[39,62,63]$. However, this result is in contrast to previous submissions by Donoghue and Donoghue [54]. In some reports, ascorbic acid exerts no significant effect on sperm motility but exhibits a profound positive effect on sperm viability [64]. Thus, the positive effect of ascorbic acid supplementation recorded in this study could be associated with the low concentration used. Ascorbic acid alone or in combination with other antioxidants may function as an antioxidant at lower concentrations; otherwise, it may serve as a pro-oxidant, leading to a massive buildup of reactive oxygen species [65]. Its function as an antioxidant could also depend on the composition of the extension media and the concentration used.

A proportional increase in morphologically abnormal spermatozoa was evident in all the preservation protocols and for all the extender preparations. This could be attributed to cellular damage due to the accumulation of metabolic byproducts, especially ROS $[12,55,66]$. Although there was no significant difference in the morphological abnormality index between egg yolk-based and soybean-based semen extenders, a significantly lower abnormality index was recorded in the ascorbic acid-supplemented fraction of both extenders. This shows the protective effect of ascorbic acid against the harmful effects of lipid peroxidation during storage, as reported previously [62,63].

This study also found a significantly higher proportion of mid-piece defects in fresh semen than in the other treatments. Alkan et al. [49] also reported that acrosomal and mid-piece defects where the most prevalent in the semen of American Bronze turkeys. In other avian species such as the emu, a similar submission was reported on their fresh semen [67]. Recently, Łukaszewicz et al. [68], working with Muscovy ducks, reported findings in line with those in this study regarding mid-piece defects. The mid-piece is the area that harbors all the spermatozoal mitochondria, which has been attributed to ROS generation through leakages in the electron transfer chain $[15,66,69,70]$. This finding echoes another report where it was clearly demonstrated that ROS generation in mitochondria has a direct causal relationship with mid-piece defects [71]. However, in extended semen, tail defects predominate in both preservation protocols. Siudzińska and Łukaszewicz [72] reported on some chicken breeds and stated that tail defects could be attributed to osmotic variations associated with extended semen.

\section{Conclusions}

It can be concluded that the two extenders (egg yolk-based and soybean-based) were similar with regard to semen quality parameters, and the two preserved turkey semen for up to $24 \mathrm{~h}$ of chilled liquid storage. It can also be concluded that ascorbic acid supplementation of the turkey semen extenders improved semen quality parameters including motility and viability and reduced the rate of morphological defects during liquid storage. Thus, the 
two extenders supplemented with L-ascorbic acid can be used to preserve turkey semen. It is obvious, however, that more studies are required to evaluate semen quality parameters using our extenders in comparison with commercial or other extenders that are already used in turkeys vis à vis fertility and hatchability. It is also pertinent to further study and optimize the level of ascorbic acid supplementation as well as exploring the effect of other antioxidants.

Supplementary Materials: The following supporting information can be downloaded at: https: / / www.mdpi.com/article/10.3390/ani12050648/s1, Table S1: Spermiogram of turkey toms enrolled in the study, Figure S1: Photomicrograph of fresh undiluted turkey semen stained with eosin-nigrosin showing live (unstained) and dead sperm (partially stained, arrow).

Author Contributions: Conceptualization, I.M.A. and S.O.A.; methodology, I.M.A., S.O.A. and M.M.B.; validation, M.C., M.M.B., M.A.W. and G.C.L.; formal analysis, I.M.A. and M.M.B.; investigation, I.M.A. and S.O.A.; resources, M.M.B. and M.A.W.; data curation, I.M.A. and S.O.A.; writing-original draft preparation, I.M.A. and M.C.; writing-review and editing, I.M.A., M.M.B., M.C. and G.C.L.; supervision, M.M.B., M.A.W. and G.C.L.; funding acquisition, M.M.B., M.A.W. and G.C.L. All authors have read and agreed to the published version of the manuscript.

Funding: This research was supported by the Tertiary Education Trust Fund (TETFund/DESS/UNIMAID/ 2018/RP/10) University of Maiduguri and by the Polish National Agency for Academic Exchange under Grant No. PPI/APM/2019/1/00044/U/00001. The authors acknowledge support from the University of Milan through the APC initiative.

Institutional Review Board Statement: The university ethics committee considers non-invasive semen collection as a routine management practice, and we fully adhered to the management guidelines stipulated.

Informed Consent Statement: Not applicable.

Data Availability Statement: Data are contained within the article.

Acknowledgments: The authors appreciate the support of P.B. for providing the space used for housing the study subjects and M.T. for technical support.

Conflicts of Interest: The authors declare no conflict of interest. The funders had no role in the design of the study; in the collection, analyses or interpretation of data; in the writing of the manuscript; or in the decision to publish the results.

\section{References}

1. Tian, S.; Xu, J.; Li, J.; Zhang, Z.; Wang, Y. Research Advances of Galliformes since 1990 and Future Prospects. Avian Res. 2018, 9 , 32. [CrossRef]

2. Hennache, A. A Review of Captive Galliformes in European Zoos. In Proceedings of the 4th International Galliformes Symposium, Chengdu, China, 14-21 October 2007; pp. 23-28.

3. Vié, J.C.; Hilton-Taylor, C.; Stuart, S.N. (Eds.) Wildlife in a Changing World: An Analysis of the 2008 IUCN Red List of Threatened Species; International Union for Conservation of Nature and Resources: Gland, Switzerland, 2009.

4. Feng, X.; Lin, C.; Qiao, H.; Ji, L. Assessment of Climatically Suitable Area for Syrmaticus Reevesii under Climate Change. Endanger. Species Res. 2015, 28, 19-31. [CrossRef]

5. Saini, M.; Das, D.K.; Dhara, A.; Swarup, D.; Yadav, M.P.; Gupta, P.K. Characterisation of Peacock (Pavo Cristatus) Mitochondrial 12s Rrna Sequence and Its Use in Differentiation from Closely Related Poultry Species. Br. Poult. Sci. 2007, 48, 162-166. [CrossRef] [PubMed]

6. Bakst, M.R.; Dymond, J.S. Artificial Insemination in Poultry. In Success in Artificial Insemination-Quality of Semen and Diagnostics Employed; InTech: Rijeka, Croatia, 2011; pp. 175-196.

7. Donoghue, A.M.; Wishart, G.J. Storage of Poultry Semen. Anim. Reprod. Sci. 2000, 62, 213-232. [CrossRef]

8. Gordon, I.R. Reproductive Technologies in Farm Animals; CABI Publishers: London, UK, 2004; pp. 49-58.

9. Kotłowska, M.; Kowalski, R.; Glogowski, J.; Jankowski, J.; Ciereszko, A. Gelatinases and Serine Proteinase Inhibitors of Seminal Plasma and the Reproductive Tract of Turkey (Meleagris gallopavo). Theriogenology 2005, 63, 1667-1681. [CrossRef] [PubMed]

10. Hess, R.A.; Thurston, R.J. Detection and Incidence of Yellow Turkey Semen on Commercial Breeder Farms. Poult. Sci. 1984, 63, 2084-2086. [CrossRef] [PubMed] 
11. Słowińska, M.; Hejmej, A.; Bukowska, J.; Liszewska, E.; Bilińska, B.; Hliwa, P.; Kozłowski, K.; Jankowski, J.; Ciereszko, A. Expression and Secretion of Albumin in Male Turkey (Meleagris gallopavo) Reproductive Tract in Relation to Yellow Semen Syndrome. Poult. Sci. 2019, 98, 1872-1882. [CrossRef] [PubMed]

12. Iaffaldano, N.; Rosato, M.P.; Manchisi, A.; Centoducati, G.; Meluzzi, A. Comparison of Different Extenders on the Quality Characteristics of Turkey Semen During Storage. Ital. J. Anim. Sci. 2005, 4, 513-515. [CrossRef]

13. Long, J.A.; Conn, T.L. Use of Phosphatidylcholine to Improve the Function of Turkey Semen Stored at $4{ }^{\circ} \mathrm{C}$ for 24 Hours. Poult. Sci. 2012, 91, 1990-1996. [CrossRef] [PubMed]

14. Sexton, T.J. Studies on the Dilution of Turkey Semen. Br. Poult. Sci. 1976, 17, 179-184. [CrossRef] [PubMed]

15. Słowińska, M.; Liszewska, E.; Judycka, S.; Konopka, M.; Ciereszko, A. Mitochondrial Membrane Potential and Reactive Oxygen Species in Liquid Stored and Cryopreserved Turkey (Meleagris gallopavo) Spermatozoa. Poult. Sci. 2018, 97, 3709-3717. [CrossRef] [PubMed]

16. Blanco, J.M.; Wildt, D.E.; Höfle, U.; Voelker, W.; Donoghue, A.M. Implementing Artificial Insemination as an Effective Tool for Ex Situ Conservation of Endangered Avian Species. Theriogenology 2009, 71, 200-213. [CrossRef] [PubMed]

17. Giesen, A.F.; Sexton, T.J. Beltsville Poultry Semen Extender. 9. Effect of Storage Temperature on Turkey Semen Held Eighteen Hours. Poult. Sci. 1983, 62, 1305-1311. [CrossRef]

18. Bakst, M.R. Fertilizing Capacity and Morphology of Fowl and Turkey Spermatozoa in Hypotonic Extender. Reproduction 1980, 60, 121. [CrossRef]

19. Sexton, T.J.; Fewlass, T.A. A New Poultry Semen Extender: 2. Effect of the Diluent Components on the Fertilizing Capacity of Chicken Semen Stored at $5{ }^{\circ}$ C. Poult. Sci. 1978, 57, 277-284. [CrossRef] [PubMed]

20. Lake, P.E.; Cherms, F.L.; Wishart, G.J. Effect of Aeration on the Fertilising Ability of Turkey Semen Stored for 48 Hours at 5 and $15^{\circ} \mathrm{C}$ : A Study from the 33rd to the 47th Week of Age. Reprod. Nutr. Develop. 1984, 24, 147-153. [CrossRef]

21. Wishart, G.J. The Effect of Continuous Aeration on the Fertility of Fowl and Turkey Semen Stored above $0{ }^{\circ} \mathrm{C}$. Br. Poult. Sci. 1981, 22, 445-450. [CrossRef] [PubMed]

22. Iaffaldano, N.; Manchisi, A.; Rosato, M.P. The Preservability of Turkey Semen Quality During Liquid Storage in Relation to Strain and Age of Males. Anim. Reprod. Sci. 2008, 109, 266-273. [CrossRef]

23. Paulenz, H.; Söderquist, L.; Pérez-Pé, R.; Andersen Berg, K. Effect of Different Extenders and Storage Temperatures on Sperm Viability of Liquid Ram Semen. Theriogenology 2002, 57, 823-836. [CrossRef]

24. Wishart, G.J. Metabolism of Fowl and Turkey Spermatozoa at Low Temperatures. Reproduction 1984, 70, 145-149. [CrossRef]

25. Amirat, L.; Tainturier, D.; Jeanneau, L.; Thorin, C.; Gérard, O.; Courtens, J.L.; Anton, M. Bull Semen in Vitro Fertility after Cryopreservation Using Egg Yolk LDL: A Comparison with Optidyl ${ }^{\circledR}$, a Commercial Egg Yolk Extender. Theriogenology 2004, 61, 895-907. [CrossRef]

26. Moussa, M.; Martinet, V.; Trimeche, A.; Tainturier, D.; Anton, M. Low Density Lipoproteins Extracted from Hen Egg Yolk by an Easy Method: Cryoprotective Effect on Frozen-Thawed Bull Semen. Theriogenology 2002, 57, 1695-1706. [CrossRef]

27. Akhter, S.; Rakha, B.A.; Andrabi, S.M.H.; Ansari, M.S. Comparison of Egg Yolks from Three Avian Species in Extender for Cryopreservation of Sahiwal Bull Epididymal Spermatozoa. Anim. Sci. Pap. Rep. 2011, 29, 131-138.

28. Santiago-Moreno, J.; Castaño, C.; Toledano-Díaz, A.; Coloma, M.A.; López-Sebastián, A.; Prieto, M.T.; Campo, J.L. Cryoprotective and Contraceptive Properties of Egg Yolk as an Additive in Rooster Sperm Diluents. Cryobiology 2012, 65, 230-234. [CrossRef]

29. Abouelezz, F.M.K.; Castaño, C.; Toledano-Díaz, A.; Esteso, M.C.; López-Sebastián, A.; Campo, J.L.; Santiago-Moreno, J. SpermEgg Penetration Assay Assessment of the Contraceptive Effects of Glycerol and Egg Yolk in Rooster Sperm Diluents. Theriogenology 2015, 83, 1541-1547. [CrossRef]

30. Bergeron, A.; Manjunath, P. New Insights Towards Understanding the Mechanisms of Sperm Protection by Egg Yolk and Milk. Mol. Reprod. Dev. 2006, 73, 1338-1344. [CrossRef]

31. Mehdipour, M.; Daghigh Kia, H.; Moghaddam, G.; Hamishehkar, H. Effect of Egg Yolk Plasma and Soybean Lecithin on Rooster Frozen-Thawed Sperm Quality and Fertility. Theriogenology 2018, 116, 89-94. [CrossRef] [PubMed]

32. Rakha, B.A.; Ansari, M.S.; Akhter, S.; Santiago-Moreno, J.; Blesbois, E. Cryoprotectant Effects of Egg Yolk on Indian Red Jungle Fowl (Gallus gallus Murghi) Sperm. Theriogenology 2018, 119, 150-155. [CrossRef] [PubMed]

33. El-Sisy, G.A.; El-Nattat, W.S.; El-Sheshtawy, R.I.; El-Maaty, A.M.A. Substitution of Egg Yolk with Different Concentrations of Soybean Lecithin in Tris-Based Extender During Bulls' Semen Preservability. Asian Pac. J. Reprod. 2016, 5, 514-518. [CrossRef]

34. Sharafi, M.; Forouzanfar, M.; Hosseini, S.M.; Hajian, M.; Ostad, H.S.; Hosseini, L.; Abedi, P.; Nili, N.; Rahmani, H.R.; Javaheri, A.R.; et al. In Vitro Comparison of Soybean Lecithin Based-Extender with Commercially Available Extender for Ram Semen Cryopreservation. Int. J. Fertil. Steril. 2009, 3, 149-152.

35. Rehman, F.U.; Qureshi, M.S.; Khan, R.U. Effect of Soybean Based Extenders on Sperm Parameters of Holstein-Friesian Bull During Liquid Storage at $4{ }^{\circ} \mathrm{C}$. Pak. J. Zool. 2014, 46, 185-189.

36. Gil, J.; Rodriguez-Irazoqui, M.; Lundeheim, N.; Söderquist, L.; Rodríguez-Martínez, H. Fertility of Ram Semen Frozen in Bioxcell ${ }^{\circledR}$ and Used for Cervical Artificial Insemination. Theriogenology 2003, 59, 1157-1170. [CrossRef]

37. Thibier, M.; Guerin, B. Hygienic Aspects of Storage and Use of Semen for Artificial Insemination. Anim. Reprod. Sci. 2000, 62, 233-251. [CrossRef]

38. Bréque, C.; Surai, P.; Brillard, J.-P. Roles of Antioxidants on Prolonged Storage of Avian Spermatozoa in Vivo and in Vitro. Mol. Reprod. Dev. 2003, 66, 314-323. [CrossRef] 
39. Tabatabaei, S. Effect of Ascorbic Acid on Chicken Semen Quality During Liquid Storage. Comp. Clin. Pathol. 2012, 21, 621-626. [CrossRef]

40. Burrows, W.H.; Quinn, J.P. The Collection of Spermatozoa from the Domestic Fowl and Turkey. Poult. Sci. 1937, 16, 19-24 [CrossRef]

41. Noirault, J.; Brillard, J.P.; Baks, M.R. Spermatogenesis in the Turkey (Meleagris gallopavo): Quantitative Approach in Mature and Adult Males Subjected to Various Photoperiods. Theriogenology 2006, 65, 845-859. [CrossRef] [PubMed]

42. Singh, A.; Singh, V.; Narwade, B.; Mohanty, T.; Atreja, S. Comparative Quality Assessment of Buffalo (Bubalus Bubalis) Semen Chilled $\left(5^{\circ} \mathrm{C}\right)$ in Egg Yolk- and Soya Milk-Based Extenders. Reprod. Domest. Anim. 2012, 47, 596-600. [CrossRef] [PubMed]

43. Ali, M.; Wu, J. Emulsifying Properties of Plasma Fractionated from Egg Yolk Using Low Centrifugal Forces-Mayonnaise Preparation. J. Food Process. Preserv. 2021, 45, e15553. [CrossRef]

44. Santiago-Moreno, J.; Castaño, C.; Toledano-Díaz, A.; Coloma, M.A.; López-Sebastián, A.; Prieto, M.T.; Campo, J.L. Semen Cryopreservation for the Creation of a Spanish Poultry Breeds Cryobank: Optimization of Freezing Rate and Equilibration Time. Poult. Sci. 2011, 90, 2047-2053. [CrossRef] [PubMed]

45. Klimowicz, M.; Łukaszewicz, E.; Dubiel, A. Effect of Collection Frequency on Quantitative and Qualitative Characteristics of Pigeon (Columba livia) Semen. Br. Poult. Sci. 2005, 46, 361-365. [CrossRef] [PubMed]

46. Macpherson, M.L. How to Evaluate Semen in the Field. In Proceedings of the Annual Convention of the AAEP, San Diego, CA, USA, 28 November 2001; pp. 412-416.

47. Agarwal, A.; Gupta, S.; Sharma, R. Eosin-Nigrosin Staining Procedure. In Andrological Evaluation of Male Infertility: A Laboratory Guide; Springer International Publishing: Cham, Switzerland, 2016; pp. 73-77.

48. Churchil, R.R.; Praveena, E.P.; Sharma, D. Semen Quality Parameters, Their Inter-Relationship and Post-Washing Sperm Attributes of Rhode Island Red Roosters. Vet. World 2014, 7, 1117-1122. [CrossRef]

49. Alkan, S.; Baran, A.; Ozdap, O.B.; Evecen, M. Morphological Defects in Turkey Semen. Turk. J. Vet. Anim. Sci. 2002, 26, 1087-1092

50. Zahradden, D.; Butswat, I.S.R.; Kalla, D.J.U.; Sir, S.M.; Bukar, M.T. Effect of Frequency of Ejaculation on Semen Characteristics in Two Breeds of Turkeys (Meleagris gallopavo) Raised in Tropical Environment. Int. J. Poult. Sci. 2005, 4, 217-221. [CrossRef]

51. Ngu, G.T.; Etchu, K.A.; Butswat, I.S.R.; Woogeng, I.N. Semen and Microbial Characteristics of Two Breeds of Turkeys in an Arid Tropical Environment of Bauchi State, Nigeria. Afr. J. Microbiol. 2014, 8, 2174-2182. [CrossRef]

52. Yahaya, M.S.; Umaru, M.A.; Aliyu, A. A Preliminary Study on Semen Collection, Evaluation and Insemination in Nigerian Local Turkeys (Meleagris gallopavo). Sokoto J. Vet. Sci. 2013, 11, 67-70. [CrossRef]

53. Bakst, M.R.; Cecil, H.C. Changes in the Characteristics of Turkey Ejaculated Semen and Ductus Deferens Semen with Repeated Ejaculations. J. Reprod. Nutr. Dev. 1981, 21, 1095-1103. [CrossRef] [PubMed]

54. Donoghue, A.M.; Donoghue, D.J. Effects of Water- and Lipid-Soluble Antioxidants on Turkey Sperm Viability, Membrane Integrity, and Motility During Liquid Storage. Poult. Sci. 1997, 76, 1440-1445. [CrossRef]

55. Douard, V.; Hermier, D.; Blesbois, E. Changes in Turkey Semen Lipids During Liquid in vitro Storage. Biol. Reprod. 2000, 63, 1450-1456. [CrossRef] [PubMed]

56. Horrocks, A.J.; Stewart, S.; Jackson, L.; Wishart, G.J. Induction of Acrosomal Exocytosis in Chicken Spermatozoa by Inner Perivitelline-Derived N-Linked Glycans. Biochem. Biophys. Res. Commun. 2000, 278, 84-89. [CrossRef]

57. Lemoine, M.; Grasseau, I.; Brillard, J.-P.; Blesbois, E. A Reappraisal of the Factors Involved in in Vitro Initiation of the Acrosome Reaction in Chicken Spermatozoa. Reproduction 2008, 136, 391. [CrossRef]

58. Layek, S.S.; Mohanty, T.K.; Kumaresan, A.; Parks, J.E. Cryopreservation of Bull Semen: Evolution from Egg Yolk Based to Soybean Based Extenders. Anim. Reprod. Sci. 2016, 172, 1-9. [CrossRef] [PubMed]

59. Aires, V.A.; Hinsch, K.-D.; Mueller-Schloesser, F.; Bogner, K.; Mueller-Schloesser, S.; Hinsch, E. In Vitro and in Vivo Comparison of Egg Yolk-Based and Soybean Lecithin-Based Extenders for Cryopreservation of Bovine Semen. Theriogenology 2003, 60, 269-279. [CrossRef]

60. Fukui, Y.; Kohno, H.; Togari, T.; Hiwasa, M.; Okabe, K. Fertility after Artificial Insemination Using a Soybean-Based Semen Extender in Sheep. J. Reprod. Dev. 2008, 54, 286-289. [CrossRef] [PubMed]

61. Masoudi, R.; Sharafi, M.; Zareh Shahneh, A.; Towhidi, A.; Kohram, H.; Esmaeili, V.; Shahverdi, A.; Davachi, N.D. Fertility and Flow Cytometry Study of Frozen-Thawed Sperm in Cryopreservation Medium Supplemented with Soybean Lecithin. Cryobiology 2016, 73, 69-72. [CrossRef]

62. Al-Daraji, H.J. Effect of Vitamin a, C \& E on Quality of Fowl Semen Stored for 24 Hours at $4{ }^{\circ}$ C. Iraqi J. Agric. $2002,7,170-181$.

63. Hu, J.-H.; Tian, W.-Q.; Zhao, X.-L.; Zan, L.-S.; Wang, H.; Li, Q.-W.; Xin, Y.-P. The Cryoprotective Effects of Ascorbic Acid Supplementation on Bovine Semen Quality. Anim. Reprod. Sci. 2010, 121, 72-77. [CrossRef] [PubMed]

64. Ceylan, A.; Serin, I. Influence of Ascorbic Acid Addition to the Extender on Dog Sperm Motility, Viability and Acrosomal Integrity During Cold Storage. Vet. Med. Rev. 2007, 158, 384-387.

65. Beconi, M.T.; Francia, C.R.; Mora, N.G.; Affranchino, M.A. Effect of Natural Antioxidants on Frozen Bovine Semen Preservation. Theriogenology 1993, 40, 841-851. [CrossRef]

66. Vernet, P.; Fulton, N.; Wallace, C.; Aitken, R.J. Analysis of Reactive Oxygen Species Generating Systems in Rat Epididymal Spermatozoa1. Biol. Reprod. 2001, 65, 1102-1113. [CrossRef] [PubMed]

67. Du Plessis, L.; Soley, J.T. Incidence, Structure and Morphological Classification of Abnormal Sperm in the Emu (Dromaius novaehollandiae). Theriogenology 2011, 75, 589-601. [CrossRef] [PubMed] 
68. Łukaszewicz, E.; Jerysz, A.; Chełmońska, B. Effect of Semen Extenders and Storage Time on Quality of Muscovy Duck (Cairina moschata) Drake Semen During the Entire Reproductive Season. Reprod. Domest. Anim. 2020, 55, 943-950. [CrossRef]

69. Chapman, D.A.; Killian, G.J.; Gelerinter, E.; Jarrett, M.T. Reduction of the Spin-Label Tempone by Ubiquinol in the Electron Transport Chain of Intact Rabbit Spermatozoa1. Biol. Reprod. 1985, 32, 884-893. [CrossRef] [PubMed]

70. Holland, M.K.; Storey, B.T. Oxygen Metabolism of Mammalian Spermatozoa. Generation of Hydrogen Peroxide by Rabbit Epididymal Spermatozoa. Biochem. J. 1981, 198, 273-280. [CrossRef]

71. Koppers, A.J.; De Iuliis, G.N.; Finnie, J.M.; Mclaughlin, E.A.; Aitken, R.J. Significance of Mitochondrial Reactive Oxygen Species in the Generation of Oxidative Stress in Spermatozoa. J. Clin. Endocrinol. Metab. 2008, 93, 3199-3207. [CrossRef] [PubMed]

72. Siudzińska, A.; Łukaszewicz, E. Effect of Semen Extenders and Storage Time on Sperm Morphology of Four Chicken Breeds. J. Appl. Poult. Res. 2008, 17, 101-108. [CrossRef] 